\title{
Causal Factors of Weld Porosity in Gas Tungsten Arc Welding of Powder-Metallurgy-Produced Titanium Alloys
}

\author{
T.R. MUTH,${ }^{1,5}$ Y. YAMAMOTO ${ }^{2}$ D.A. FREDERICK, ${ }^{1}$ C.I. CONTESCU, ${ }^{3}$ \\ W. CHEN,${ }^{1}$ Y.C. LIM, ${ }^{1}$ W.H. PETER, ${ }^{4}$ and Z. FENG ${ }^{1}$ \\ 1.-Materials Processing and Joining Group, Oak Ridge National Laboratory, One Bethel Road, \\ Oak Ridge, TN 37831, USA. 2.-Alloy Behavior and Design Group, Oak Ridge National Labora- \\ tory, One Bethel Road, Oak Ridge, TN 37831, USA. 3.-Carbon and Composites Group, Oak Ridge \\ National Laboratory, One Bethel Road, Oak Ridge, TN 37831, USA. 4.-Material Science and \\ Technology Division, Oak Ridge National Laboratory, One Bethel Road, Oak Ridge, TN 37831, \\ USA. 5.—e-mail: muthtr@ornl.gov
}

\begin{abstract}
An investigation was undertaken using gas tungsten arc (GTA) welding on consolidated powder metallurgy (PM) titanium (Ti) plate to identify the causal factors behind observed porosity in fusion welding. Tramp element compounds of sodium and magnesium, residual from the metallothermic reduction of titanium chloride used to produce the titanium, were remnant in the starting powder and were identified as gas-forming species. PM-titanium made from revert scrap, where sodium and magnesium were absent, showed fusion weld porosity, although to a lesser degree. We show that porosity was attributable to hydrogen from adsorbed water on the surface of the powders prior to consolidation. The removal and minimization of both adsorbed water on the surface of titanium powder and the residues from the reduction process prior to consolidation of titanium powders are critical for achieving equivalent fusion welding success similar to that seen in wrought titanium produced via the Kroll process.
\end{abstract}

\section{BACKGROUND}

Titanium and titanium alloys produced via the Kroll reduction process, which are subsequently melt refined and wrought processed into mill forms such as bar and plate in modern titanium plants, have excellent quality, high integrity, and they are metallurgically uniform. (The aforementioned production process will hereafter be designated as the Kroll route for producing titanium.) Fusion welding is commonly used to fabricate large or complex geometry structures from titanium mill forms. Extensive studies have been conducted by previous researchers in the joining of Kroll route alloys by conventional fusion welding processes, including gas metal arc welding, ${ }^{1}$ gas tungsten arc (GTA) welding, ${ }^{2}$ laser beam welding, ${ }^{3}$ and electron beam welding. 4,5

For Kroll route titanium, controls to ensure welding success revolve around the cleanliness of cover gas, prevention of atmospheric contamination during the weld thermal cycle, and cleanliness of the surfaces of both the feed wire and the base metal. In addition to cleanliness control, control of heat input is also required to avoid vaporization of alloying elements that may cause porosity and deleterious microstructural features. Fusion welding, while avoiding environmental contaminants, with a controlled heat input, reliably results in a porosityfree weld with an acceptable microstructure.

Significant efforts have taken place over the last decade to establish powder metallurgy titanium from a number of reduction technologies that yield a particulate, as an alternative to the Kroll route. ${ }^{6}$ The impetus has been to lower the energy input for producing titanium components by eliminating melting and improving yield. The expected results of the powder metallurgy (PM) efforts were to broaden the use of titanium, while making it affordable for industrial use. There have been modest breakthroughs in niche areas where titanium produced via powder metallurgy has found acceptance ${ }^{7}$; however, the comparison between titanium mill forms produced via the Kroll route 
and mill forms produced via the PM route requires consideration, particularly as it pertains to welding.

Consolidation of powder metallurgy titanium (PM-Ti) is a thermomechanical process whereby powder is either hot consolidated in an inert environment or cold consolidated under normal atmospheric conditions. Further densification of cold consolidated powder is accomplished by a thermal treatment, hot mechanical working, or both. The hot mechanical work is performed in an inert environment to maintain the necessary oxygen and nitrogen purity needed for maintaining good mechanical properties. Table I shows the nitrogen and oxygen compositions of powders from varying sources before and after full consolidation. It is observed that oxygen levels increase in consolidated PM-Ti over the starting powders, even when great care is taken to deny gaseous oxygen exposure during processing. Nitrogen levels would be expected to increase threefold over oxygen if the sources for oxygen were air, but nitrogen levels remain low. It is suspected that adsorbed water on the surface of the titanium powder prior to consolidation is the source of increased oxygen values. It is further suspected that the adsorbed water is also a source of hydrogen dissolved as an interstial element in consolidated PM-Ti and that when fusion welding is performed, hydrogen gas is evolved.

The source for adsorbed water is humidity from the air. When materials are exposed to atmospheric conditions, the ever present water vapor clings to the surface according the bonding energy for water at that surface. Water is a polar molecule composed of an oxygen atom with two hydrogen atoms bonded $105^{\circ}$ apart. When a water molecule adsorbs onto a metal surface, it forms a bond with a binding energy of approximately $23 \mathrm{kcal} / \mathrm{mole} .^{8}$ Successive molecular layers of water build up on previous layers, with progressively less binding energy.

The removal of adsorbed water on metal surfaces is a common challenge for those operating highvacuum systems. Great care is taken to minimize the surface area in those systems, such that the amount of water vapor requiring removal is kept to a minimum; hence, polished surfaces that minimize surface area fare much better than mill-finished surfaces, for ease of water vapor removal. To achieve the required vacuum levels needed in highvacuum systems, heating of the metal surfaces is typically employed. Moderate heating in the $350^{\circ} \mathrm{C}$ range for several hours removes molecular layers of water that are less tightly bound; however, heating above $900^{\circ} \mathrm{C}$ is required to remove the innermost layers. ${ }^{9}$

Consider the high surface area associated with titanium powders prior to consolidation, which vary from $0.1 \mathrm{~m}^{2} / \mathrm{g}$ for hydride dehydride (HDH) powders to $1.7 \mathrm{~m}^{2} / \mathrm{g}$ for Armstrong process powders. Due to the chemical reactivity of titanium, heating the powders to remove adsorbed water, similar to the way high-vacuum systems are dehydrated, results

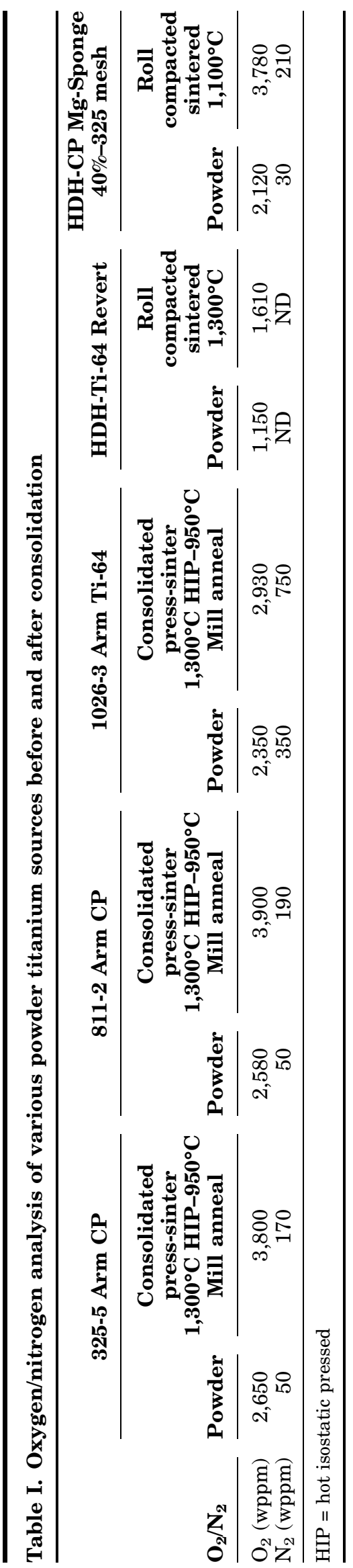



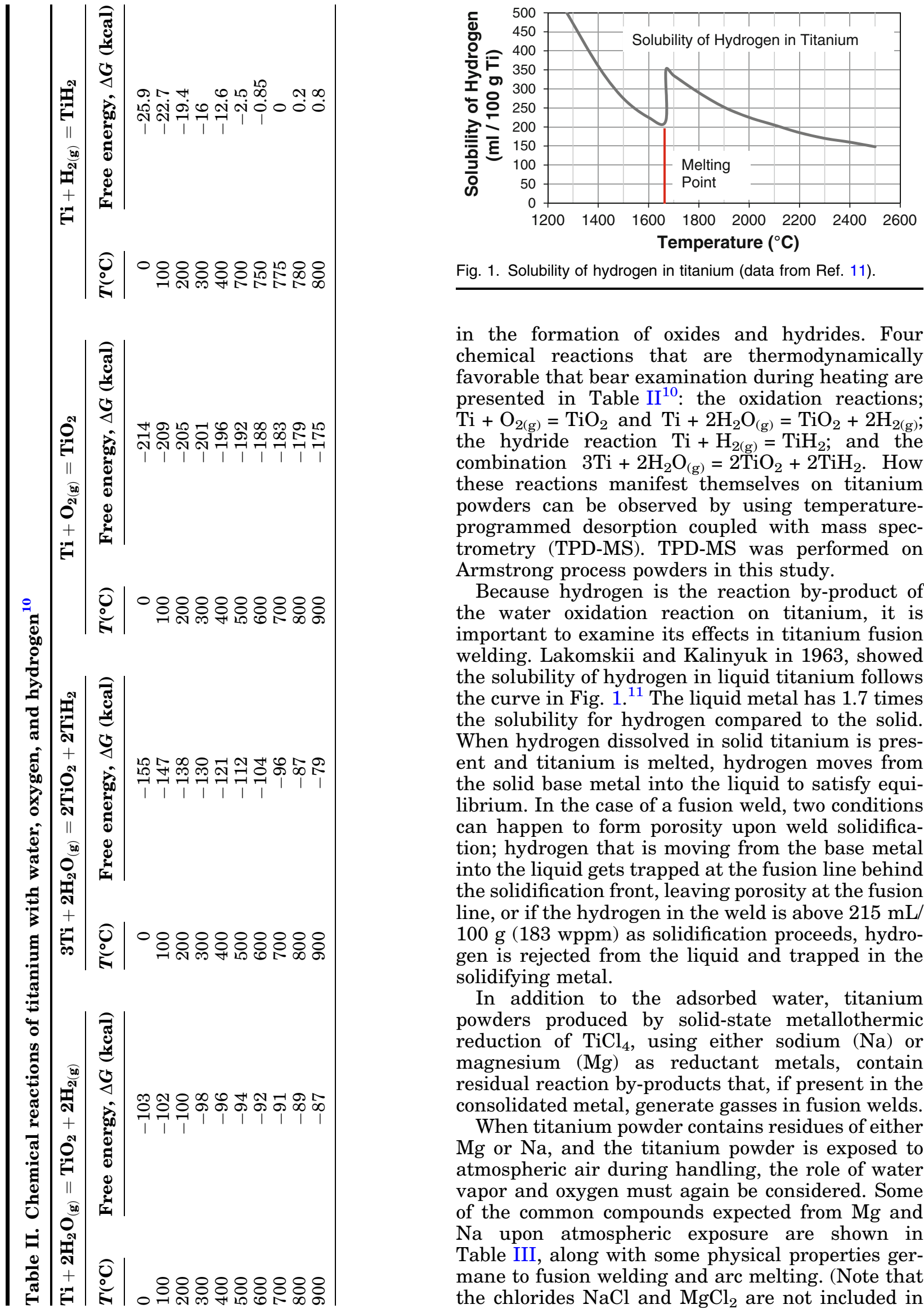

Fig. 1. Solubility of hydrogen in titanium (data from Ref. 11).

in the formation of oxides and hydrides. Four chemical reactions that are thermodynamically favorable that bear examination during heating are presented in Table $\mathrm{II}^{10}$ : the oxidation reactions; $\mathrm{Ti}+\mathrm{O}_{2(\mathrm{~g})}=\mathrm{TiO}_{2}$ and $\mathrm{Ti}+2 \mathrm{H}_{2} \mathrm{O}_{(\mathrm{g})}=\mathrm{TiO}_{2}+2 \mathrm{H}_{2(\mathrm{~g})}$; the hydride reaction $\mathrm{Ti}+\mathrm{H}_{2(\mathrm{~g})}=\mathrm{TiH}_{2}$; and the combination $3 \mathrm{Ti}+2 \mathrm{H}_{2} \mathrm{O}_{(\mathrm{g})}=2 \mathrm{TiO}_{2}+2 \mathrm{TiH}_{2}$. How these reactions manifest themselves on titanium powders can be observed by using temperatureprogrammed desorption coupled with mass spectrometry (TPD-MS). TPD-MS was performed on Armstrong process powders in this study.

Because hydrogen is the reaction by-product of the water oxidation reaction on titanium, it is important to examine its effects in titanium fusion welding. Lakomskii and Kalinyuk in 1963, showed the solubility of hydrogen in liquid titanium follows the curve in Fig. $1 .^{11}$ The liquid metal has 1.7 times the solubility for hydrogen compared to the solid. When hydrogen dissolved in solid titanium is present and titanium is melted, hydrogen moves from the solid base metal into the liquid to satisfy equilibrium. In the case of a fusion weld, two conditions can happen to form porosity upon weld solidification; hydrogen that is moving from the base metal into the liquid gets trapped at the fusion line behind the solidification front, leaving porosity at the fusion line, or if the hydrogen in the weld is above $215 \mathrm{~mL} /$ $100 \mathrm{~g}$ (183 wppm) as solidification proceeds, hydrogen is rejected from the liquid and trapped in the solidifying metal.

In addition to the adsorbed water, titanium powders produced by solid-state metallothermic reduction of $\mathrm{TiCl}_{4}$, using either sodium (Na) or magnesium $(\mathrm{Mg})$ as reductant metals, contain residual reaction by-products that, if present in the consolidated metal, generate gasses in fusion welds.

When titanium powder contains residues of either $\mathrm{Mg}$ or $\mathrm{Na}$, and the titanium powder is exposed to atmospheric air during handling, the role of water vapor and oxygen must again be considered. Some of the common compounds expected from $\mathrm{Mg}$ and $\mathrm{Na}$ upon atmospheric exposure are shown in Table III, along with some physical properties germane to fusion welding and arc melting. (Note that the chlorides $\mathrm{NaCl}$ and $\mathrm{MgCl}_{2}$ are not included in 
Table III. Common compounds of suspected tramp species in PM-Ti

\begin{tabular}{|c|c|c|c|c|c|}
\hline Species & $\begin{array}{l}\text { Molecular } \\
\text { weight }\end{array}$ & $\begin{array}{c}\text { Melting } \\
\text { point }\left({ }^{\circ} \mathbf{C}\right)\end{array}$ & $\begin{array}{c}\text { Boiling } \\
\text { point }\left({ }^{\circ} \mathbf{C}\right)\end{array}$ & $\begin{array}{c}\text { Oxygen } \mathrm{g} \\
\text { of } \mathrm{O}_{2} / \mathrm{g} \text { of species }\end{array}$ & $\begin{array}{c}\text { Hydrogen } \mathrm{g} \\
\text { of } \mathrm{H}_{2} / \mathrm{g} \text { of species }\end{array}$ \\
\hline $\mathrm{Ti}$ & 47.86 & 1,668 & 3,287 & 0 & 0 \\
\hline $\mathrm{TiO}_{2}$ & 79.86 & 1,843 & 2,972 & 0.4 & 0 \\
\hline $\mathrm{Mg}$ & 24.3 & 714 & 1,091 & 0 & 0 \\
\hline $\mathrm{MgO}$ & 40.3 & 2,852 & 3,600 & 0.79 & 0 \\
\hline $\mathrm{Mg}(\mathrm{OH})_{2}$ & 58.3 & dis 350 & - & 0.55 & 0.03 \\
\hline $\mathrm{Na}$ & 23 & 98 & 1,413 & 0 & 0 \\
\hline $\mathrm{Na}(\mathrm{OH})$ & 40 & 318 & 1,388 & 0.4 & 0.01 \\
\hline $\mathrm{Na}_{2} \mathrm{O}$ & 62 & 1,132 & 1,950 & 0.26 & 0 \\
\hline
\end{tabular}

Table IV. Reactions of Na compounds with $\mathrm{Ti}$ to produce $\mathrm{Na}$ metal ${ }^{10}$

\begin{tabular}{|c|c|c|c|}
\hline \multicolumn{2}{|c|}{$\begin{array}{l}\mathbf{2 N a O H}+\mathbf{T i}= \\
\mathbf{T i O}_{2}+\mathbf{H}_{2}(\mathrm{~g})+\mathbf{2 N a}\end{array}$} & \multicolumn{2}{|c|}{$\begin{array}{l}2 \mathrm{Na}_{2} \mathrm{O}+\mathbf{T i}= \\
\mathrm{TiO}_{2}+4 \mathbf{N a}\end{array}$} \\
\hline$T\left({ }^{\circ} \mathbf{C}\right)$ & $\begin{array}{c}\text { Free energy } \\
\quad \Delta G \text { (kcal) }\end{array}$ & $T\left({ }^{\circ} \mathrm{C}\right)$ & $\begin{array}{c}\text { Free energy } \\
\Delta G \text { (kcal) }\end{array}$ \\
\hline 0 & -30.4 & 0 & -32.3 \\
\hline 100 & -33.3 & 100 & -34.1 \\
\hline 200 & -36.6 & 200 & -36.6 \\
\hline 300 & -39.8 & 300 & -39.2 \\
\hline 400 & -42.4 & 400 & -41.7 \\
\hline 500 & -44.8 & 500 & -44.2 \\
\hline 600 & -47.0 & 600 & -46.6 \\
\hline 700 & -49.1 & 700 & -48.9 \\
\hline 800 & -51.2 & 800 & -51.1 \\
\hline 900 & -53.1 & 900 & -53.2 \\
\hline 1000 & -54.9 & 1000 & -55.0 \\
\hline 1100 & -56.6 & 1100 & -56.4 \\
\hline 1200 & -58.3 & 1200 & -56.6 \\
\hline 1300 & -59.9 & 1300 & -56.3 \\
\hline
\end{tabular}

the list. An analysis on consolidated PM titanium in this study showed the absence of chlorides.)

Magnesium as a tramp metal in elemental form has a boiling point of $1,091^{\circ} \mathrm{C}$. This is well below the melting point of titanium and could cause gas evolution in a weld, where temperatures exceed $1,800^{\circ} \mathrm{C}$. (Kroll route processing eliminates $\mathrm{Mg}$ and $\mathrm{Mg}$ compounds in the multiple consumable vacuum arc melting processes.) If $\mathrm{Mg}$ were present as magnesium oxide $(\mathrm{MgO})$ in the starting powder, then upon exposure to normal atmospheric air, $\mathrm{MgO}$ would convert to $\mathrm{Mg}(\mathrm{OH})_{2}$, the stable roomtemperature species. Upon heating, $\mathrm{Mg}(\mathrm{OH})_{2}$ decomposes to $\mathrm{MgO}$ and $\mathrm{H}_{2(\mathrm{~g})}$ at $350^{\circ} \mathrm{C} .{ }^{12}$ The speed of the decomposition is well within the time/temperature cycle used to consolidate powders to a fully dense plate. The expected result is for $\mathrm{MgO}$ solid to be remnant in a matrix of titanium alloy that contains dissolved hydrogen or the compound $\mathrm{TiH}_{2}$. Hydrogen therefore should be considered a source of porosity in fusion welds of PM-Ti containing residual magnesium. The MgO by-product of the dissociation should remain as slag or as a nonmetallic inclusion for the short-time weld thermal cycle.

When the $\mathrm{TiCl}_{4}$ reduction process uses sodium, consideration is given to elemental sodium. Sodium is not stable as a metal under normal atmospheric conditions; $\mathrm{NaOH}$ and $\mathrm{Na}_{2} \mathrm{O}$ are deemed the likely species at room temperature. However, during consolidation of the titanium powders in an inert environment, at elevated temperature, with $\mathrm{NaOH}$ and $\mathrm{Na}_{2} \mathrm{O}$ present, some reduction reactions are expected to convert the sodium compounds back to elemental sodium. Those considered reactions are listed in Table $\mathrm{IV}^{10}$ and show a negative Gibbs free energy $(\Delta G)$, indicating the reaction is thermodynamically favorable in the range of temperatures where powder consolidation occurs. Recognizing that the reactions are solid-state reactions, requiring intimacy of reacting species for the reactions to proceed, it is reasonable to consider that all three $\mathrm{Na}, \mathrm{NaOH}$, and $\mathrm{Na}_{2} \mathrm{O}$ are present in consolidated powders, where the powders are produced via sodium reduction. $\mathrm{Na}$ and $\mathrm{NaOH}$ are both gasses below the liquidus of titanium. $\mathrm{Na}_{2} \mathrm{O}$ has a higher boiling point, $1,950^{\circ} \mathrm{C}$, and if trapped in the liquid of a fusion weld, it can either decompose or evaporate if the weld is superheated. All three sodium species are candidates likely to cause gas evolution during fusion welding.

It is suspected that these internal contaminants are the underlying reason why the welding protocols used to eliminate external contaminants for Kroll route produced metal do not result in similar weld quality in PM-Ti. Experiments to confirm the role of these contaminants are the subject of this study.

\section{EXPERIMENTAL WORK}

Reactivity of powder titanium below $1,000^{\circ} \mathrm{C}$ was studied using a TPD-MS technique to understand the role of adsorbed water on titanium prior to and during consolidation. The objective was to see if hydrogen is a contributing species to porosity in fusion welds on 

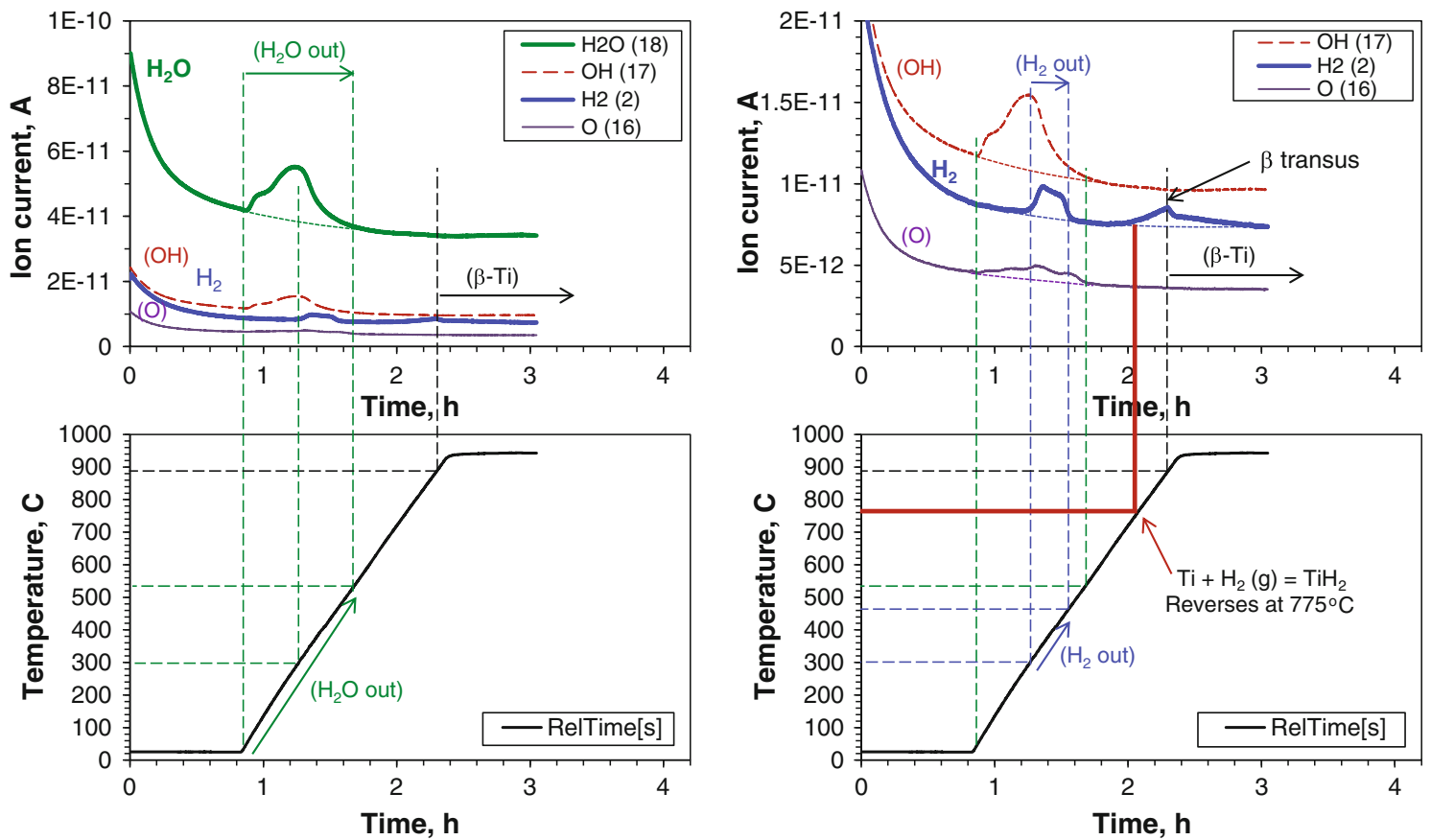

Fig. 2. TPD-MS curves generated during the heating of Armstrong process powders at a rate of $10^{\circ} \mathrm{C}$ per min.

PM-Ti. In addition to the TPD-MS work, the poor fusion welding malaise observed in PM-Ti was highlighted using GTA welding techniques on consolidated powders. To augment the GTA welding trials, arc melting was performed on several PM-Ti alloys to allow longer observation of the molten metal. The longer observation times and larger sample sizes associated with arc melting allowed some conclusions to be drawn about the sources of gas-induced porosity in PM-Ti fusion welds.

\section{Desorption Analysis of Titanium Powder}

A sample of Armstrong process, commercially pure (CP) titanium, with a composition of 2,350 weight parts per million (wppm) $\mathrm{O}_{2}$ and 246 wppm $\mathrm{N}_{2}$ was placed in a Quantachrome 1C (Quantachrome Instruments, Boynton Beach, FL) TPD-MS machine under flowing helium. Sampling of the offgas through the mass spectrometer during the heating cycle resulted in the diagrams shown in Fig. 2. The top left diagram is the examined spectrum as a function of time. The $Y$-axis scale is ion current, ranging from $1 \times 10^{-10}$ amperes to $1 \times 10^{-13}$ amperes. The bottom left diagram is the corresponding time/temperature cycle used to heat the sample. The time portions of the two left-side diagrams are aligned so that time/temperature and gas species are synchronized. The two right-hand diagrams are similar to the left-hand diagrams except the scale for ion current is magnified to the range of $2 \times 10^{-11}$ to $2 \times 10^{-12}$, to allow detailed observation of the hydrogen curve.

The heating cycle began with a room-temperature hold for $50 \mathrm{~min}$ in flowing helium, followed by a $10^{\circ} \mathrm{C}$ per minute heating rate to $950^{\circ} \mathrm{C}$. The analysis showed that during the 50-min room-temperature cycle, $\mathrm{H}_{2} \mathrm{O}_{(\mathrm{g})}, \mathrm{H}_{2(\mathrm{~g})}, \mathrm{OH}_{(\mathrm{g})}$, and $\mathrm{O}_{(\mathrm{g})}$ diminished with time by an exponential decay curve. $(\mathrm{OH}$ with $\mathrm{m} / \mathrm{z}=17$ and $O$ with $\mathrm{m} / \mathrm{z}=16$ were tracked in parallel with water to confirm the signal $\mathrm{m} / z=18$ was from $\mathrm{H}_{2} \mathrm{O}_{(\mathrm{g})}$. Both $\mathrm{OH}_{(\mathrm{g})}$ and $\mathrm{O}_{(\mathrm{g})}$ are fragments of ionized $\mathrm{H}_{2} \mathrm{O}_{(\mathrm{g})}$ induced by the magnetic field and accelerating voltage in the detector inside the mass spectrometer.) Once heating commenced, an increase in $\mathrm{H}_{2} \mathrm{O}_{(\mathrm{g})}, \mathrm{OH}_{(\mathrm{g})}$ and $\mathrm{O}_{(\mathrm{g})}$ was registered in the mass spectrometer with a peak occurring at $300^{\circ} \mathrm{C}$. Beyond $300^{\circ} \mathrm{C}, \mathrm{H}_{2} \mathrm{O}_{(\mathrm{g})}$ diminished while $\mathrm{H}_{2(\mathrm{~g})}$ showed an increase. Hydrogen evolution diminished to the normal decay curve above $450^{\circ} \mathrm{C}$, where it once again followed the expected decay curve. At $775^{\circ} \mathrm{C}$, hydrogen was detected and increased up to $885^{\circ} \mathrm{C}$ where again it was seen to diminish.

An explanation of the TDP-MS data is proposed. During the 50-min room-temperature hold, free water from humidity exposure is evolving from the powder surface, indicated by the diminishing concentration of all species in this range. Between room temperature and $300^{\circ} \mathrm{C}$, the outermost layers of adsorbed $\mathrm{H}_{2} \mathrm{O}$ are desorbing, indicated by the ascending curve for water in this range. At $300^{\circ} \mathrm{C}$, $\mathrm{H}_{2} \mathrm{O}$ desorption is diminishing, and the oxidation reaction $\mathrm{Ti}+2 \mathrm{H}_{2} \mathrm{O}_{(\mathrm{g})}=\mathrm{TiO}_{2}+2 \mathrm{H}_{2(\mathrm{~g})}$ begins with $\mathrm{H}_{2(\mathrm{~g})}$ evolving as evidenced by the ascending $\mathrm{H}_{2}$ curve at $300^{\circ} \mathrm{C}$. Between $300^{\circ} \mathrm{C}$ and $450^{\circ} \mathrm{C}$, the evolving hydrogen has two reactionary paths: $\mathrm{H}_{2(\mathrm{~g})}$ can form $\mathrm{TiH}_{2}$ according to the reaction $\mathrm{Ti}+$ $\mathrm{H}_{2(\mathrm{~g})}=\mathrm{TiH}_{2}$ or $\mathrm{H}_{2(\mathrm{~g})}$ can dissolve into the alpha titanium as interstitial hydrogen according to equilibrium. ${ }^{13}$ Evidence that $\mathrm{TiH}_{2}$ forms explains 
the second evolution of hydrogen seen to begin at $775^{\circ} \mathrm{C}$. At $775^{\circ} \mathrm{C}$, the hydrogen concentration curve reaches a minimum at the temperature where delta $G$ turns positive for the reaction $\mathrm{Ti}+\mathrm{H}_{2(\mathrm{~g})}=\mathrm{TiH}_{2}$ (Table II). From $775^{\circ} \mathrm{C}$ to $885^{\circ} \mathrm{C}, \mathrm{TiH}_{2}$ continues to dissociate as indicated by the ascending curve, until $885^{\circ} \mathrm{C}$ is reached. At $885^{\circ} \mathrm{C}$, the beta transus is reached where hexagonal closed-packed alpha titanium transforms to body-centered cubic beta titanium. (Beta titanium at $885^{\circ} \mathrm{C}$ can dissolve $\mathrm{H}_{2(\mathrm{~g})}$ to $10,500 \mathrm{wppm}$ as an interstial species compared to a solubility of less than $30 \mathrm{wppm}$ for alpha titanium at $\left.880^{\circ} \mathrm{C}^{13}\right)$ Hence $\mathrm{H}_{2(\mathrm{~g})}$, dissolves into beta titanium at $885^{\circ} \mathrm{C}$, resulting in a diminished detection of hydrogen in the mass spectrometer. The second reactionary path for hydrogen at $300^{\circ} \mathrm{C}$ is the dissolution of hydrogen into alpha titanium. That path cannot be validated in this analysis.

Because the sample form in the TPD-MS is loose powder, under flowing helium, evolving hydrogen can be detected. If the powder were consolidated to $50 \%$ to $80 \%$ as is typical for PM consolidation, and subsequently thermally treated in a vacuum or inert furnace, as is the typical practice for PM-Ti, then it is likely the majority of the evolving hydrogen would be consumed by the aforementioned reactions prior to escaping into the free space of a furnace. The result is an increase in both oxygen content via oxidation and hydrogen content via solid-state dissolution. In general, the higher the surface area of the starting titanium powder, the higher the increase in hydrogen and oxygen upon consolidation. Armstrong process powders show higher increases in oxygen upon consolidation than do $\mathrm{HDH}$ powders, due to the surface area difference.

\section{Plate Sources for GTA Welding and Arc Melting}

Four sources of plate material made from powdered titanium, 6 wt.\% aluminum, 4 wt.\% vanadium
(Ti-64), and two sources of plate made from CP powders, are shown in Table V. Table V also shows the composition of two commercial wrought alloys incorporated in the study for comparison, KW-Ti-64 and KW-CP. The Ti-64 plates were produced from Armstrong process powder (X1-ITP-Ti-64, and X2-ITP-Ti-64) (Cristal Metals, Lockport, IL) and hydride dehydride powder (HDH-Ti-64) (Reading Alloys, Robesonia, PA). The HDH-Ti-64 powder was manufactured from revert scrap from Kroll route source material at Reading Alloys. Oak Ridge National Laboratory (ORNL) also purchased Ti-64 plate for this work from ADMA Products (ADMATi-64; Hudson, OH), a commercial, PM-Ti plate producer. The two sources of commercially pure titanium powders were consolidated into plate via vacuum hot pressing. The HDH-CP powder source was from Global Titanium, Inc. (Detroit, MI). The X3-ITP-CP powder was from Cristal Metals.

Since the study was limited to plates previously consolidated, there was a variation in methods of consolidation. In the case of the Ti-64 alloy X1-ITPTi-64, consolidation was by vacuum hot pressing Armstrong process powders at $1,300^{\circ} \mathrm{C}$ into a 150 $\mathrm{mm}$ diameter disk. The plate was cut from the pressed disk via electrode discharge machining. Upon cross-sectional examination of the machined plate, porosity was observed and the plate was subsequently hot rolled at $950^{\circ} \mathrm{C}$, taking a $20 \%$ reduction to achieve full consolidation at a $6-\mathrm{mm}$ thickness. X2-ITP-Ti-64 was vacuum hot pressed to full density and hot forged in air at a forging temperature of $950^{\circ} \mathrm{C}$. Porosity was observed in the ADMA-Ti-64 plate prior to welding and it was hot rolled at $950^{\circ} \mathrm{C}$ with a $20 \%$ reduction to achieve full density at a $6-\mathrm{mm}$ thickness. The HDH-Ti-64 was consolidated by HIP at $925^{\circ} \mathrm{C}$ in a steel can, followed by machining to produce a rectangular weld coupon. The HIP'ed, HDH-Ti-64 appeared fully dense and no further processing was required. The CP titanium plates were both produced by vacuum hot pressing at

Table V. Compositions of PM-Ti consolidated plate

\begin{tabular}{|c|c|c|c|c|c|c|c|c|}
\hline \multirow[b]{2}{*}{ Species } & \multicolumn{5}{|c|}{ Source plate Ti-64 } & \multicolumn{3}{|c|}{ Source plate CP-Ti } \\
\hline & KW-Ti-64 & ADMA Ti-64 & X1-ITP Ti-64 & X2-ITP Ti-64 & HDH Ti-64 & KW-CP & HDH CP & X3-ITP CP \\
\hline $\mathrm{Al}(\mathrm{wt} . \%)$ & - & 5.97 & 5.85 & 6.68 & 6.28 & - & - & - \\
\hline $\mathrm{V}($ wt.\%) & - & 4.08 & 5.76 & - & - & - & - & - \\
\hline $\mathrm{Fe}($ wt.\%) & - & 0.046 & 0.022 & - & - & - & - & - \\
\hline $\mathrm{Cl}$ (wppm) & $<10$ & $<10$ & $<10$ & - & $<10$ & $<10$ & $<10$ & $<10$ \\
\hline $\mathrm{Na}$ (wppm) & - & 720 & 26 & 48 & - & - & - & 240 \\
\hline Mg (wppm) & $<5$ & 10 & $<5$ & $<5$ & $<5$ & $<5$ & 92 & - \\
\hline $\mathrm{N}_{2}($ wppm $)$ & 90 & 210 & 6230 & 325 & 250 & 120 & 80 & 290 \\
\hline $\mathrm{O}_{2}($ wppm $)$ & 1590 & 2480 & 3720 & 4235 & 1390 & 144 & 2280 & 3135 \\
\hline \multirow[t]{2}{*}{$\mathrm{H}_{2}(\mathrm{wppm})$} & 18 & 48 & 160 & 17 & 150 & 15 & 120 & 44 \\
\hline & $\mathrm{M}$ & $\mathrm{W}$ & $\mathrm{W}$ & M & $\mathrm{W} \& \mathrm{M}$ & $\mathrm{M}$ & $\mathrm{M}$ & M \\
\hline
\end{tabular}

$W$ Welded via GTA, $M$ Melted via nonconsumable electrode vacuum arc 
$1,100^{\circ} \mathrm{C}$. Full density in both plates was observed after hot pressing.

Noteworthy in the compositions of Table $\mathrm{V}$ are that X1-ITP-Ti-64 has high nitrogen, oxygen, hydrogen, and vanadium compared to ASTM B265-Gr5 specifications. The tramp element sodium, residual from the reduction process, is present in X1-ITP-Ti-64,
X2-ITP-Ti-64, and X3-ITP-CP. The HDH-Ti-64 material shows a hydrogen level equal to the maximum of the ASTM B265-Gr5 specification (150 wppm); all other elements fall within the desired range. ADMA-Ti-64 shows higher oxygen, $2,480 \mathrm{wppm}$, compared to the $2,000 \mathrm{wppm}$ limits in the ASTM B265-Gr5 specification. All other species
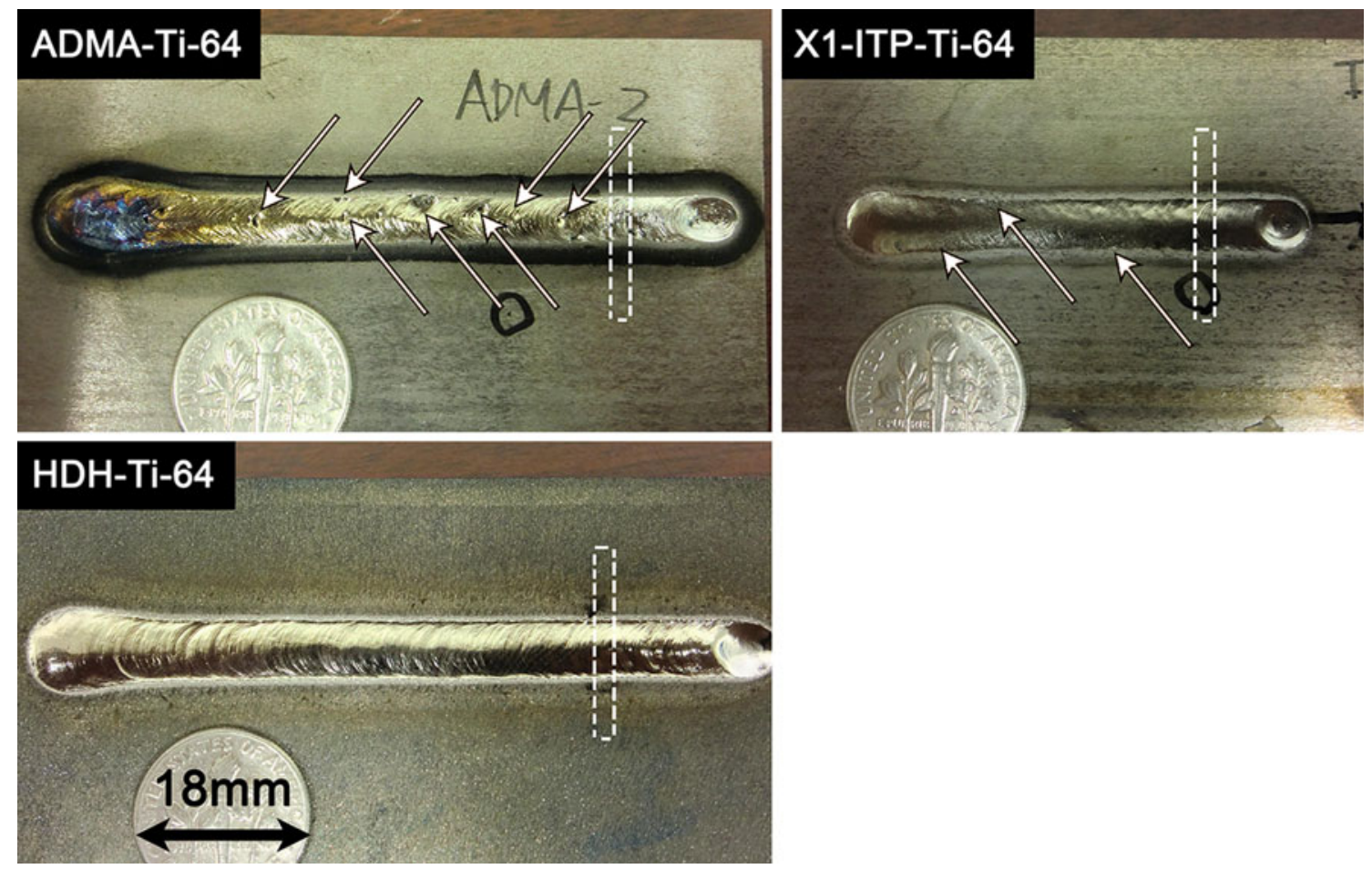

Fig. 3. Plan view of autogenous GTA welds on PM-Ti alloy plates from three different sources. The white boxes denote the zones where cross sections were taken for the images in Fig. 4.
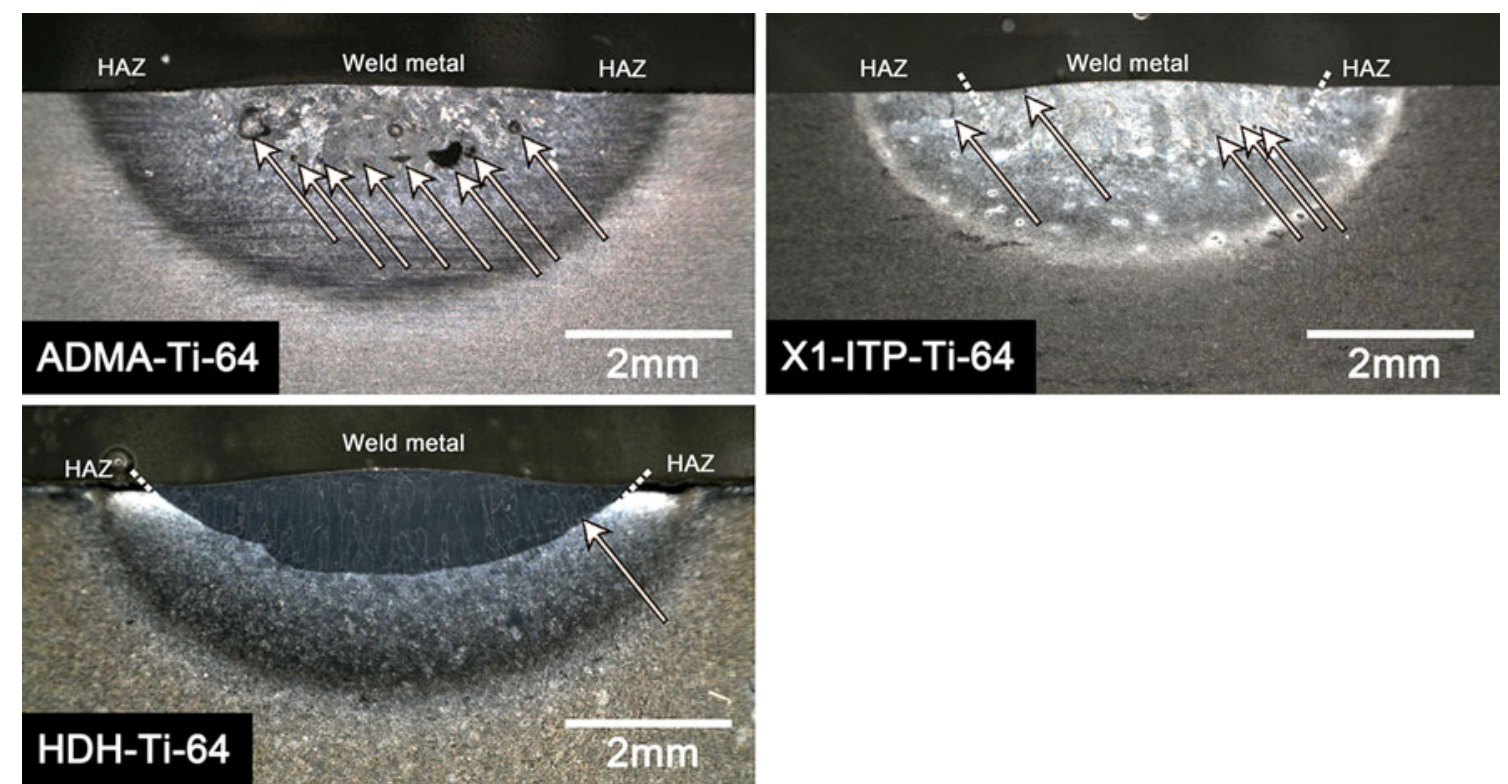

Fig. 4. Cross sectional view of the GTA welds showing the significant porosity in the ADMA-Ti-64, lesser but still present in X1-ITP-Ti-64, and minor in $\mathrm{HDH}-\mathrm{Ti}-64$. 
in ADMA-Ti-64 fall within the specification limits, although detectable levels of both magnesium and sodium are present.

\section{Fusion Welding}

Autogenous GTA welding was performed on 6-mm-thick plate from ADMA-Ti-64, X1-TI-64, and HDH-Ti-64 material sources. The cover gas was high-purity argon. The calculated heat input for the welds, using Eq. 1, was $93.6 \mathrm{~kJ} / \mathrm{m}$. $Q$ is the heat input in megajoules per meter, $\eta$ is arc efficiency (0.48 for GTA welding) ${ }^{14} E$ is electrode voltage $(11 \mathrm{~V}), I$ is electrode current $(120 \mathrm{~A})$, and $v$ is travel speed in meters per second $\left(6.77 \times 10^{-3} \mathrm{~m} / \mathrm{s}\right)$.

$$
Q=\eta \frac{\mathrm{EI}}{v}
$$

A plan view of the fusion welds is shown in Fig. 3 with the metallographic cross sections of each shown in Fig. 4 at the places indicated.

Significant porosity was visible on the surface and in the cross-sectional images of X1-ITP-Ti-64 and ADMA-Ti-64 as shown in Figs. 3 and 4. The HDH-Ti-64 had a smooth surface appearance with minor porosity identified in the cross section.

From the compositions shown in Table V the tramp elements sodium and magnesium in the case of ADMA-Ti-64 and sodium alone in the case of X1-ITP-Ti-64, stand out as likely causes for the porosity.

In the case of the HDH-Ti-64 plate, the porosity seen at the fusion line in Fig. 4 is likely due to hydrogen evolution.

To provide further evidence that the residual tramp element compounds of sodium and magnesium were the cause of the gross porosity in ADMA-Ti-64 and X1-ITP-Ti-64, and that hydrogen was the likely source in HDH-Ti-64, arc melting was performed on plates of X2-ITP-Ti-64 and HDH-Ti-64.

\section{Arc Melting}

A nonconsumable tungsten electrode arc melter, running in 0.5 atmospheres of high-purity argon at 450 amperes, was used to melt 9 to $13 \mathrm{~g}$ cuboid coupons of the consolidated PM-Ti alloys whose compositions are depicted in Table VI. Figure 5 is a photograph of a coupon in the water-cooled copper crucible prior to melting. A molten pool was sustained for $30 \mathrm{~s}$ for each alloy source material while visual observations were made. Following cool down, the solidified masses were sectioned for

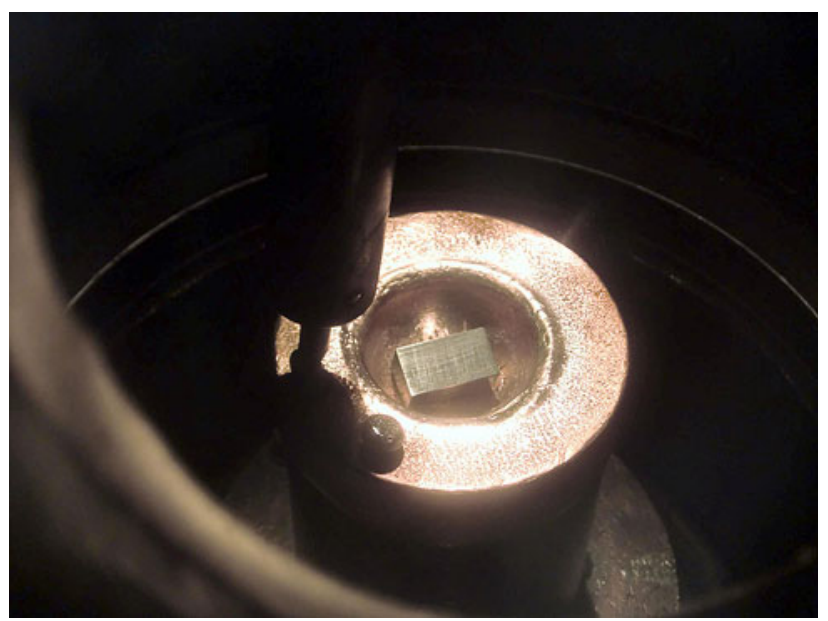

Fig. 5. Photograph of arc-melting coupon in the water-cooled copper crucible prior to melting.

Table VI. Compositions of PM-Ti consolidated plate before and after arc melting

\begin{tabular}{|c|c|c|c|c|c|c|c|c|}
\hline \multirow[b]{2}{*}{ Species } & \multirow{2}{*}{\multicolumn{2}{|c|}{ Melt condition }} & \multicolumn{3}{|c|}{ Source plate-Ti-64 } & \multicolumn{3}{|c|}{ Source plate Ti-Cp } \\
\hline & & & X2-ITP-Ti-64 & HDH-Ti-64 & KW-Ti-64 & X3-ITP-Cp & HDH-Cp & KW-Cp-Ti \\
\hline \multirow[t]{2}{*}{$\mathrm{Al}(\mathrm{wt} . \%)$} & & Pre & 6.68 & 6.28 & 6.26 & - & - & \\
\hline & Post & & 7.12 & - & 6.32 & - & - & \\
\hline \multirow[t]{2}{*}{$\mathrm{V}(\mathrm{wt} . \%)$} & & Pre & - & - & - & - & - & \\
\hline & Post & & - & - & - & - & - & \\
\hline \multirow[t]{2}{*}{$\mathrm{Fe}($ wt.\%) } & & Pre & - & - & - & - & - & \\
\hline & Post & & - & - & - & - & - & \\
\hline \multirow[t]{2}{*}{$\mathrm{Na}($ wppm $)$} & & Pre & 48 & - & - & 240 & - & \\
\hline & Post & & $<5$ & - & - & $<5$ & - & \\
\hline \multirow[t]{2}{*}{ Mg (wppm) } & & Pre & - & $<5$ & $<5$ & $<5$ & 92 & $<5$ \\
\hline & Post & & - & $<5$ & $<5$ & $<5$ & $<5$ & $<5$ \\
\hline \multirow{2}{*}{$\mathrm{N}_{2}$ (wppm) } & & Pre & 310 & 250 & 9 & 290 & 80 & 120 \\
\hline & Post & & 340 & 260 & 10 & 310 & 90 & 120 \\
\hline \multirow{2}{*}{$\mathrm{O}_{2}(\mathrm{wppm})$} & & Pre & 4235 & 1390 & 1590 & 3135 & 2280 & 1440 \\
\hline & Post & & 3940 & 1430 & 1780 & 3055 & 2345 & 1340 \\
\hline \multirow{2}{*}{$\mathrm{H}_{2}$ (wppm) } & & Pre & 17 & 150 & 18 & 44 & 120 & 15 \\
\hline & Post & & 10 & 51 & 16 & 19 & 54 & 18 \\
\hline
\end{tabular}


compositional analysis using direct current plasma emission spectroscopy for alloying elements and LECO interstitial analysis for oxygen, nitrogen, and hydrogen (LECO Corporation, St. Joseph, MI).

The arc melting observations, where the molten pool was held for a minimum of $30 \mathrm{~s}$, showed disturbances caused by evolving gas in all the PM-Ti melts. Aggressive disturbance was observed in the X2-ITP-Ti-64: vigorous in the initial $10 \mathrm{~s}$ and less so but still active at termination $(30 \mathrm{~s})$. Moderate molten pool disturbance was observed in the $\mathrm{HDH}-\mathrm{Ti}-64$ but ceased after $10 \mathrm{~s}$ and remained quiet for the duration of the 30-s hold. The KW-Ti64 showed no disturbances. Examining the premelt and postmelt compositional values, a reduction in sodium from 48 wppm to nondetectable levels was shown in the X2-ITP-Ti-64 sample. A reduction in oxygen from 4,235 wppm to $3,190 \mathrm{wppm}$ is unexplained in the X2-ITP-Ti-64 sample and requires further investigation. A reduction in hydrogen is also observed from 17 to $10 \mathrm{wppm}$.

The analytical results and the visual observations allow some speculation to be considered. If sodium were present in the starting material as $\mathrm{NaOH}$ or $\mathrm{Na}_{2} \mathrm{O}$, in the case of X2-ITP-Ti-64, upon heating to liquid, $\mathrm{NaOH}$ would likely either boil $\left(1,388^{\circ} \mathrm{C}\right)$ or convert to $\mathrm{Na}_{2} \mathrm{O}$ evolving hydrogen. The $\mathrm{Na}_{2} \mathrm{O}$ would either reduce to $\mathrm{Na}$ and boil $\left(1,413^{\circ} \mathrm{C}\right)$ or remain as solid $\mathrm{Na}_{2} \mathrm{O}$, until some superheat in the molten pool forced the $\mathrm{Na}_{2} \mathrm{O}$ to boil $\left(1,950^{\circ} \mathrm{C}\right)$. $\mathrm{Na}$ boiling may account for the early vigor. A timetemperature-dependent sustained release where $\mathrm{Na}_{2} \mathrm{O}$ boils or slowly dissociates in the presence of molten titanium reasonably explains the sustained disturbance observed in X2-ITP-Ti-64.

The postmelt analysis where bulk hydrogen dropped from $17 \mathrm{wppm}$ to $10 \mathrm{wppm}$ indicates hydrogen evolution during melting. The sodium level went to nondetectable levels indicating complete release of sodium as a gas. If $\mathrm{Na}_{2} \mathrm{O}$ was the sodium-containing species and $\mathrm{Na}_{2} \mathrm{O}$ boiled, then a drop in oxygen level could be explained as seen in the analysis; however, if all the sodium (48 wppm) were $\mathrm{Na}_{2} \mathrm{O}$, that would equate to less than 20 wppm oxygen reduction, in contrast to the measured 245 wppm reduction. The reduced oxygen remains unexplained. It would have been beneficial to have arc melted ADMA-Ti-64 to further examine the apparent deoxidizing effect of sodium. The study did not allow that to occur.

In the case of HDH-Ti-64, early moderate disturbance could be attributable to hydrogen. A reduction in hydrogen from 150 wppm to 51 wppm occurred. Recall that the HDH-Ti-64 plate was produced from revert scrap, meaning that Kroll route material was reduced to a metal hydride powder by the hydride dehydride process and then consolidated. The triple-melt purification of the titanium alloy in the Kroll route material, prior to hydride/dehydride processing, eliminated the residual magnesium as indicated by the premelt composition.

The KW-Ti-64 had little or no change in hydrogen and was calm throughout the 30 -s melt, indicating no gas species were evolved during arc melts.

\section{CONCLUSIONS}

Powder-metallurgy-produced titanium cannot yet be reliably fusion welded due to weld porosity. The role of water vapor on the surface of titanium powder is one causal factor of the porosity. Water vapor has two effects; it increases the oxygen content of the consolidated powder via an oxidation reaction, and it increases the hydrogen content of the consolidated powder through a reaction dynamic that eventually ends up with hydrogen dissolved as an interstitial element in the consolidated base metal.

The porosity is also caused by internal contaminants: magnesium compounds in the case of $\mathrm{Mg}$ reduced $\mathrm{TiCl}_{4}$, and sodium compounds in the case of Na-reduced $\mathrm{TiCl}_{4}$. The contaminants are remnants of the reduction process, and if not removed prior to fusion welding, they become significant gas-forming species.

The challenge of removing the tramp compounds of sodium and magnesium without melting remains. Efforts to remove those tramp compounds by thermal distillation in the case of $\mathrm{Mg}$ compounds and aqueous removal in the case of sodium compounds is ongoing. To economically remove absorbed water or render its effects negligible is a significant challenge for PM-Ti. Work is underway at ORNL to find a remedy.

\section{REFERENCES}

1. Y.M. Zhang and P.I. Li, Weld. J. 80, 54S (2001)

2. M. Balasubramanian, V. Jayabalan, and V. Balasubramanian, Mater. Lett. 62, 1102 (2008)

3. X. Cao and M. Jahazi, Opt. Laser Eng. 47, 1231 (2009).

4. K.P. Rao, K. Angamuthu, and P.B. Srinivasan, J. Mater. Process. Tech. 199, 185 (2008).

5. S.G. Wang and X.Q. Wu, Mater. Des. 36, 663 (2012).

6. E. Kraft, Summary of Emerging Titanium Cost Reduction Technologies-A Study Performed for the U.S. Department of Energy and Oak Ridge National Laboratory (Vancouver, WA: EHK Technologies, 2004).

7. D. Eylon, F.H. Froes, and S. Abkowitz, ASM Handbook, Vol. 7 (Materials Park, OH: ASM International, 1998), pp. 874-886.

8. P. Danielson, R\&D Magazine (April 2005), pp. 27-28.

9. Y. Ishikawa and T. Yoshimura, J. Vac. Sci. Technol. A 13, 1847 (1995).

10. HSC Chemistry 7, Thermodynamic software (Espoo, Finland: Outotec Research Center).

11. V.I. Lakomskii and N.N. Kalinyuk, Avt. Svarka. 9, 31 (1963).

12. B.V. L'vov, A.V. Novichikhin, and A.O. Dyakov, Thermochim. Acta 315, 135 (1998).

13. K. Nakamura, H-Ti Phase Diagram, ASM Alloy Phase Diagrams Center, ed. H. Okamoto and K. Cenzual (Materials Park, OH: ASM International, 2006-2013).

14. K. Easterling, Introduction to the Physical Metallurgy of Welding (Oxford, UK: Butterworths \& Co. Ltd., 1983). 